\title{
Changes in subcellular localization reveal interactions between human cytomegalovirus terminase subunits
}

\author{
Jian Ben Wang ${ }^{1}$, Yali Zhu' ${ }^{2}$, Michael A McVoy ${ }^{1 *}$ and Deborah S Parris ${ }^{2}$
}

\begin{abstract}
Background: During herpesvirus replication, terminase packages viral DNA into capsids. The subunits of herpes simplex virus terminase, UL15, UL28, and UL33, assemble in the cytoplasm prior to nuclear import of the complex.

Methods: To detect similar interactions between human cytomegalovirus terminase subunits, the orthologous proteins UL89, UL56, and UL51 were expressed in HEK-293 T cells (via transfection) or insect cells (via baculovirus infection) and subcellular localizations were detected by cellular fractionation and confocal microscopy.

Results: In both cell types, UL56 and UL89 expressed alone were exclusively cytoplasmic, whereas UL51 was 50\% nuclear. Both UL89 and UL56 became 50\% nuclear when expressed together, as did UL56 when expressed with UL51. Nuclear localization of each protein was greatest when all three proteins were co-expressed.

Conclusions: These results support inclusion of UL51 as an HCMV terminase subunit and suggest that nuclear import of human cytomegalovirus terminase may involve nuclear import signals that form cooperatively upon subunit associations.
\end{abstract}

Keywords: Herpesvirus, Cytomegalovirus, Terminase, DNA packaging, Genome maturation

\section{Background}

Herpesviruses have large $(130$ - $235 \mathrm{~kb})$ linear doublestranded DNA genomes that replicate via concatemeric intermediates consisting of head-to-tail linked genomes. An enzyme complex called terminase functions to package the DNA into preformed capsids and cleave the concatemers at precise locations to release unit length genomes within the capsids [1]. The herpes simplex virus type 1 (HSV-1) proteins UL15, UL28, and UL33 are believed to comprise the HSV-1 terminase. Studies have also detected interactions between UL56 and UL89 $[2,3]$, the human cytomegalovirus (HCMV) orthologs of HSV-1 UL28 and UL15, respectively. The possible inclusion of UL51 as part of the HCMV terminase has been inferred as it is an ortholog of HSV-1 UL33. Here, we show evidence that co-expression of UL56 with UL89 or UL56 with UL51 is necessary for nuclear import of

\footnotetext{
* Correspondence: mmcvoy@vcu.edu

'Department of Pediatrics, Virginia Commonwealth University, P.O. Box 163, MCV Station, Richmond, VA 23298-0163, USA

Full list of author information is available at the end of the article
}

UL56 or UL89 in the absence of any other viral proteins. These results suggest that UL51 is a component of the HCMV terminase and that specific interactions among terminase subunits in the cytoplasm are prerequisites for its nuclear importation.

\section{Results}

Each subunit was expressed using recombinant baculoviruses. PCR overlap extension was used to modify the 5 ' end of the UL51 ORF to encode an N-terminal FLAG epitope. Sf9 insect cells were infected with $3 \mathrm{pfu} / \mathrm{cell}$ of each baculovirus individually, or co-infected with pairwise combinations or with all three viruses. After $48 \mathrm{~h}$, soluble cytoplasmic and nuclear fractions were prepared and analyzed by immunoblotting. UL56 and UL89 were detected using polyclonal rabbit antisera and UL51 was detected using a FLAG epitope-specific mouse monoclonal antibody. To ensure efficient separation of nuclear from cytoplasmic material, blots were also probed with antibodies to the exclusively cytoplasmic protein (tubulin) or to the exclusively nuclear protein (histone H4). 
When expressed alone, UL51 (17 kDa) was equally distributed between the cytoplasm and the nucleus, whereas UL56 (96 kDa) and UL89 (77 kDa) were found exclusively in the cytoplasm (Figure 1). Distribution of UL51 was not significantly affected by co-expression with other proteins; however, dual expression of UL56 with either UL51 or UL89 resulted in redistribution of about half of the UL56 to the nucleus. Similarly, dual expression of UL89 with UL56 resulted in redistribution of about half of the UL89 to the nucleus. When all three proteins were expressed, each protein appeared to be equally distributed between cytoplasmic and nuclear fractions (Figure 1).

To determine if similar localization patterns occur in human cells, mammalian plasmid expression vectors were engineered to express UL51, UL56, or UL89 fused to N-terminal FLAG, V5, or MYC epitope tags, respectively. HEK-293 T cells were transfected with plasmid vectors individually or in combinations. After $48 \mathrm{~h}$ the cells were permeabilized and the subcellular localization of each protein was determined by confocal microscopy using fluorescent-tagged epitope-specific monoclonal antibodies (Figure 2). UL51 was often found in both the cytoplasm and the nucleus, with $41 \%$ of cells exhibiting nuclear staining. This proportion was not significantly altered by the presence of the other proteins. UL56 was exclusively cytoplasmic when expressed alone, but the percentage of cells with nuclear staining increased to $62 \%$ in the presence of UL51, 37\% in the presence of UL89, and 74\% when all three proteins were present. UL89 was also exclusively cytoplasmic when expressed alone, but unlike UL56, its localization was not affected by co-expression of UL51. However, the percentage of cells with UL89 nuclear staining increased to $26 \%$ in the presence of UL56 and to $80 \%$ when all three proteins were present (Figure 2).

\section{Discussion}

The results from these experiments suggest that when expressed individually, both UL56 and UL89 are strictly cytoplasmic but co-expression promotes nuclear localization of both proteins. This could be a result of each protein harboring a partial nuclear localization signal (NLS) that is functional only when the two proteins interact, or due to protein interactions that alter conformation of at least one component to expose an otherwise hidden NLS. In either case, the data suggest that UL56 and UL89 interact. That UL56 can localize to the nucleus when co-expressed with UL51 also suggests that UL56 and UL51 interact in the cytoplasm to form a complex that can be transported to the nucleus. Again, interaction with UL51 could promote conformational changes that expose an NLS within UL56, or translocation of the complex could be mediated by an NLS in UL51. It is uncertain whether UL51 contains an NLS as its small size $(\sim 17 \mathrm{kDa})$ should allow nuclear entry independent of the nuclear pore complex.

While these results indicate that the two-subunit UL51/56 or UL56/89 complexes can form in the cytoplasm and subsequently localize to the nucleus, it cannot be ascertained from our studies whether all three proteins interact to form three-subunit UL51/56/89 complexes. Moreover, while we observed no evidence for UL51-UL89 interaction, it is possible that interactions

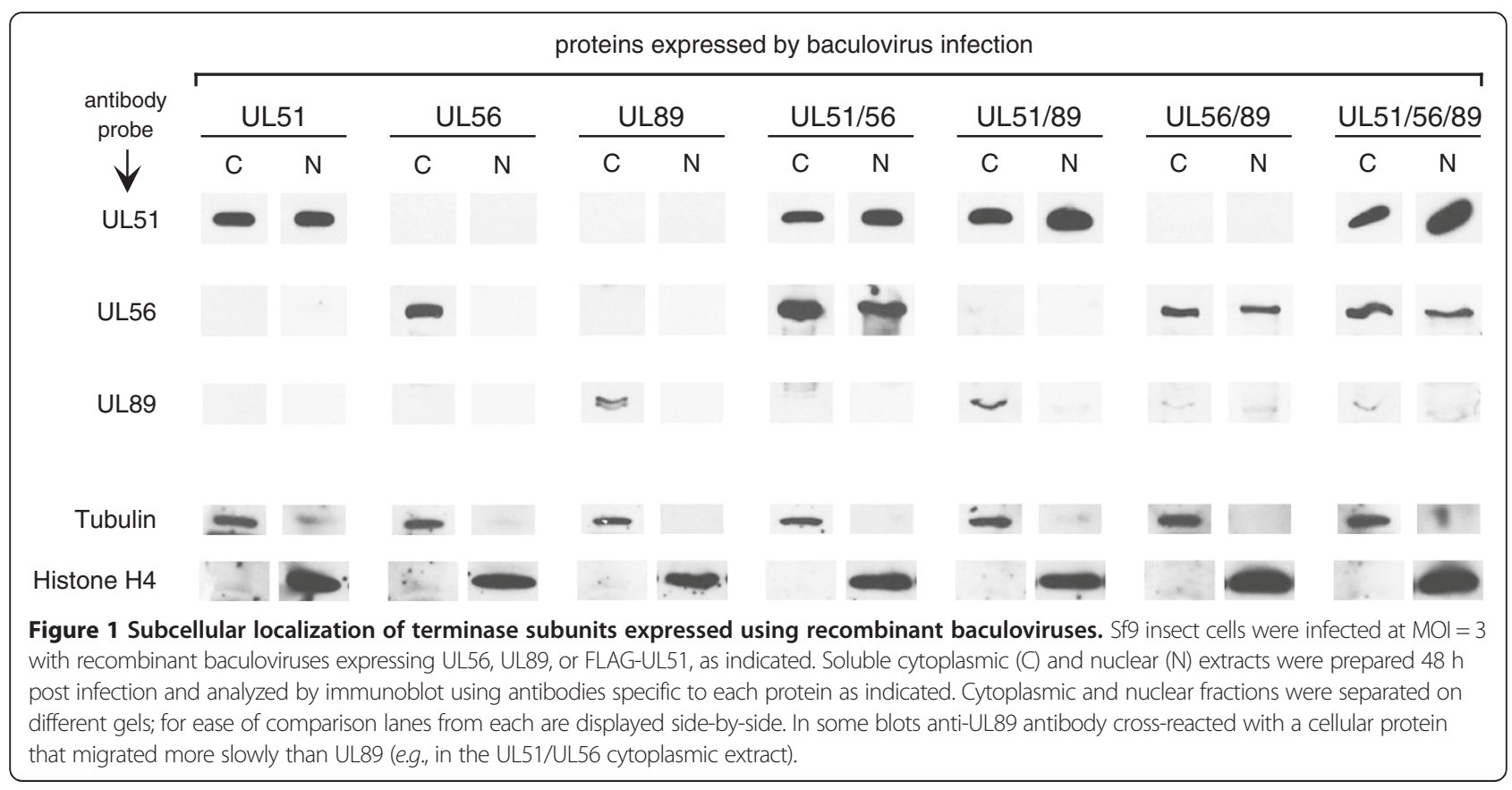




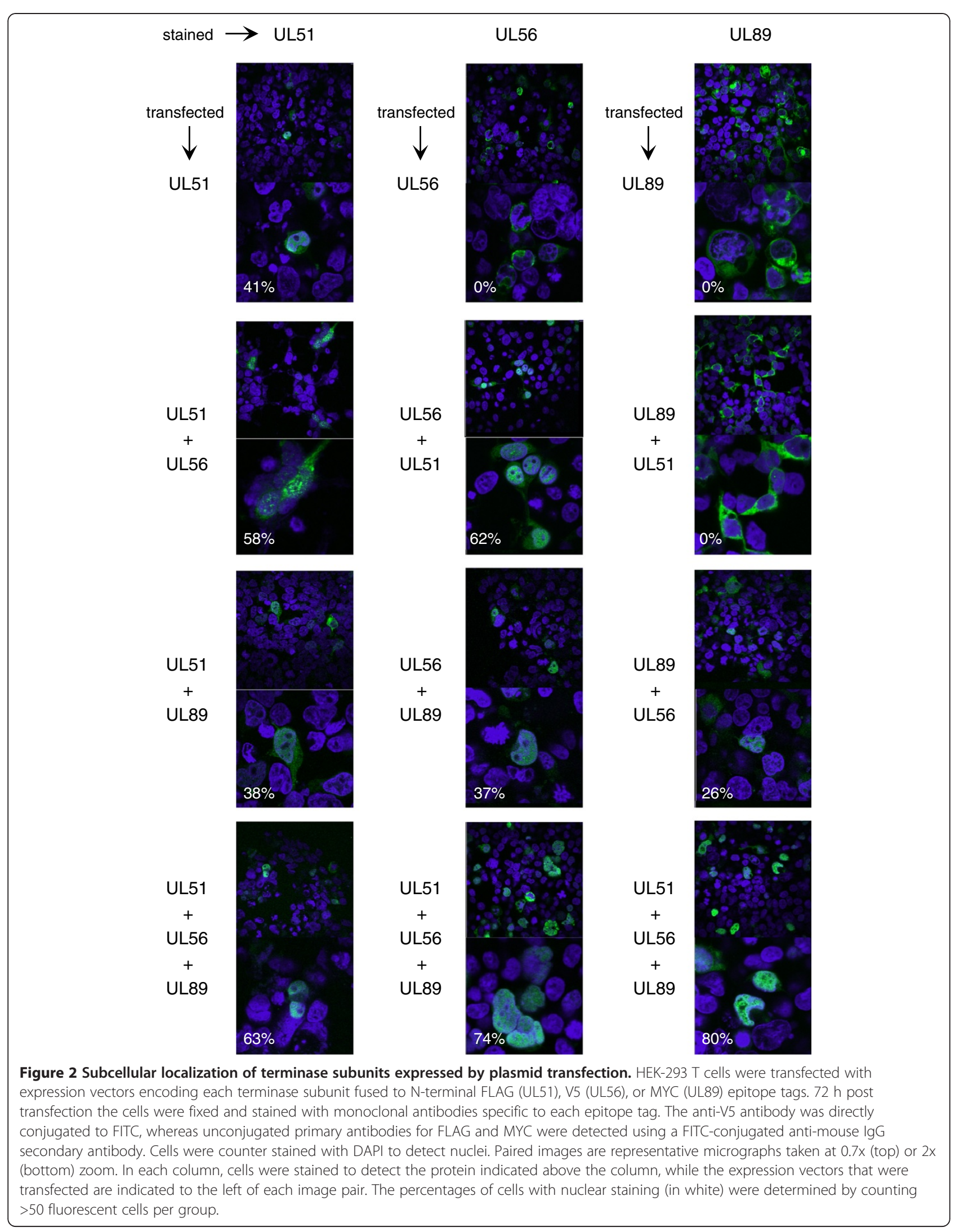


were missed due to epitope tags on plasmid-expressed proteins or baculovirus-expressed UL51. A paper published following submission of this report confirms an essential role for UL51 in DNA packaging and demonstrates that each protein co-precipitates the other two [4]. Even so, co-precipitation or nuclear colocalization could be due to the ability of UL56 to interact independently with UL51 and UL89. However, if this were the case, the presence of UL51 should not increase the nuclear localization of UL89 in cells expressing all three proteins, but rather, UL51 might impair the nuclear localization of UL89 by competing for UL56 binding. In fact, in our studies nuclear localization of UL89, UL56, and UL51 all increased significantly when all three proteins were co-expressed in transfected $293 \mathrm{~T}$ cells (Figure 2).

In agreement with our results, Borst et al. demonstrated that nuclear localization of UL89 and UL56 was severely diminished, though not apparently eliminated, in HCMV-infected cells when UL51 was knocked down [4]. Surprisingly, these authors were unable to detect cytoplasmic localization of UL89 and/or UL56 by immunofluorescence when UL51 protein was severely diminished. However, since knock down of UL51 did not impact immunoblot levels of UL89 or UL56, it is likely that immunofluorescence was not sensitive enough to detect these proteins when they were dispersed in the cytoplasm. Taken together, these data suggest that threesubunit complexes likely form in the cytoplasm and are more efficiently imported to the nucleus when all are present, because of cooperativity between the NLS formed between UL56 and UL89 and perhaps between UL56 and UL51, or because of conformational changes induced by interactions that expose a nuclear localization signal. The proposed interactions that effect transport of the terminase holoenzyme and its putative subunits are summarized in Figure 3.

Interactions between terminase subunits were first suggested by observations that the UL28 proteins of pseudorabies virus or HSV-1 are translocated to the nucleus when co-expressed with the UL15 protein of HSV1 and that they co-purify as a complex in infected cells [5-7]. Subsequent studies implicated UL33 as an additional subunit of terminase complexes [8] and demonstrated direct UL28-UL15 and UL28-UL33 interactions and a UL28-dependent indirect interaction between UL15 and UL33 [9-13]. Our studies indicate functional interactions between HCMV orthologs UL56 and UL89 and between UL56 and UL51. Moreover, data reported by Borst et al. after our findings were submitted for publication indicate that UL51, UL89, and UL56 coprecipitate from HCMV-infected cell lysates, further suggesting that all three proteins exist in the same complex [4]. Interactions between terminase subunit orthologs of varicella zoster virus, Kaposi's sarcomaassociated herpesvirus, and murine cytomegalovirus (MCMV) have also been reported [14-17].

The studies presented here are the first to characterize the intracellular trafficking of UL89 outside the context of infected cells and they directly implicate UL51 as a subunit of the HCMV terminase by virtue of its interaction with UL56. Borst et al. [4] also implicate UL51 as an essential member of the HCMV terminase complex since, despite normal levels of DNA replication, DNA cleavage and genome packaging into virions fail to occur when UL51 is knocked down in HCMV-infected cells. Because we were able to track localization of each subunit when expressed alone or with each of the other proteins, we were able to demonstrate an interdependence between UL56 and UL89 for nuclear transport even in the absence of UL51. This is consistent with prior reports of UL56-UL89 interaction and their colocalization to nuclear viral replication centers in HCMV-infected cells $[2,3,18,19]$. However, contrary to our findings, Giesen et al. detected UL56 in the nuclei of transfected COS7 cells in the absence of other HCMV proteins and mapped a putative NLS [18]. This may suggest that UL56 localization is cell type-dependent as

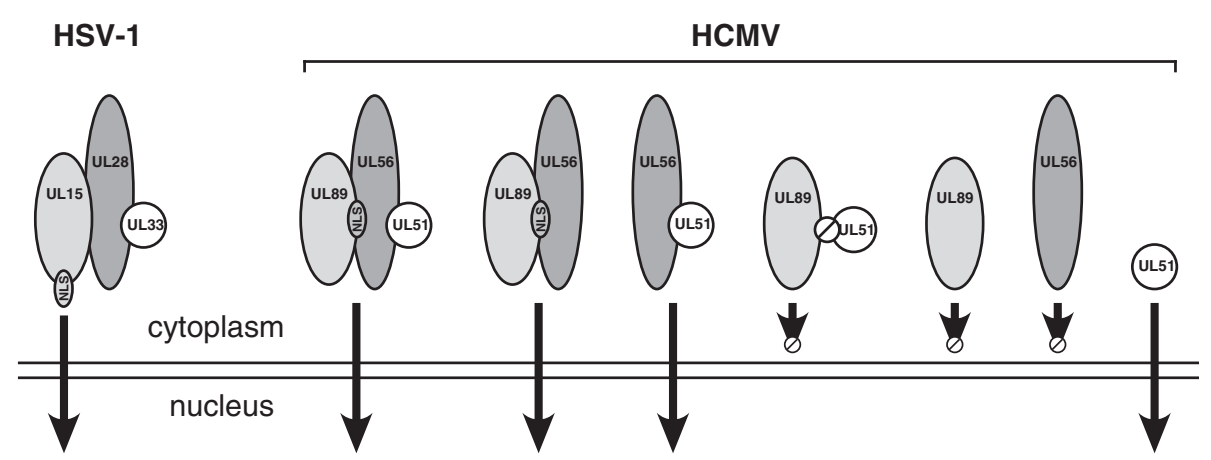

Figure 3 Summary of terminase subunit interactions for HSV-1 and HCMV. HCMV terminase subunit complexes that result in nuclear transport are illustrated. NLS, nuclear localization signal; $\varnothing$, no interaction, no nuclear translocation. 
UL56 failed to localize to the nuclei of insect cells or human HEK-293 $\mathrm{T}$ cells in our studies. It should be pointed out that neither our studies nor those of Borst et al. [4] have demonstrated direct protein-protein interactions between subunits despite the fact that they co-localize or co-precipitate. However, even if such interactions are indirect, our studies indicate that they do not involve an additional viral protein, although a cellular protein present in both insect and human cells could be required. Work is in progress to rule out such a possibility.

Thus, despite strong sequence conservation between orthologous terminase subunits, it appears that HCMV and HSV-1 have evolved subtle differences in nuclear import of terminase complexes. For HSV-1 import of terminase to the nucleus relies on an overt NLS in UL15, whereas in HCMV the orthologous subunit (UL89) clearly lacks nuclear transport capacity. Terminase instead appears to rely on nuclear import signals formed cooperatively between the three subunits. Nevertheless a common theme is emerging that terminase must assemble in the cytoplasm before it can move to the nucleus. Presumably this restriction serves an important purpose, perhaps preventing uncomplexed or incorrectly complexed subunits from exerting detrimental effects on the cleavage/packaging process.

The specific function of HCMV UL51 or its orthologs, remains unknown. Given that HSV-1 UL33 enhances the UL15-UL28 interaction [9] and that HCMV UL51 (or all three of the putative terminase subunits) is required for efficient nuclear localization of these subunits, a role for UL33 or UL51 orthologs in promoting or stabilizing optimal terminase conformation can be envisioned. Moreover, the report that the varicella zoster virus UL33 ortholog exhibits a plethora of interacting partners [16] has fueled speculation that UL33-family proteins may serve a more general role in stabilizing protein complexes [14]. Recent interactome analyses of the UL33 orthologs of MCMV and varicella zoster virus revealed interactions with tegument proteins as well proteins involved in transport of newly formed viral capsids across the nuclear membrane [17,20]. Such findings, combined with evidence that UL51 and its MCMV ortholog are present in virions [21,22], suggest that UL33-family proteins may mediate or stabilize proteinprotein interactions that link DNA encapsidation with post-packaging processes of tegumentation and nuclear egress $[17,20]$.

\section{Conclusions}

The results support inclusion of UL51 as an HCMV terminase subunit and suggest that nuclear import of HCMV terminase may involve nuclear import signals that form cooperatively upon subunit associations. In recent years DNA maturation has emerged as a target for development of novel antivirals. Several "maturational" inhibitors have been identified [23-28]. Letermovir (AIC246), a recent candidate with potent activity against HCMV, has entered phase IIb clinical trials [29-32]. Dissection of the mechanisms of action of these inhibitors and identification of additional candidates would be considerably advanced by a better understanding of the structure and functions of terminase subunits and the holoenzyme.

\section{Methods}

Plasmid and baculovirus expression vector construction

Oligonucleotide primers used for vector construction are listed in Table 1. The UL51 coding sequence was PCR amplified from HCMV strain AD169 DNA with primer pair MOL269/MOL270 and ligated into PCR-XLTOPO (Invitrogen) to make plasmid pMA319. An XbaI/ HindIII fragment of pMA319 containing UL51 sequences was then ligated into XbaI/HindIII-restricted pFastbac1 (Invitrogen) to make plasmid pMA320. FLAG-UL51 expression plasmid pMA323 was constructed by PCR amplification of pMA320 with primer pair UL51-FLAG-H3F/ UL51-FLAG-ER1R (which introduce flanking HindIII and EcoRI sites) and ligation of the HindIII/EcoRI-digested PCR product into HindIII/EcoRI-digested pcDNA2FLAGAB, a modification of pcDNA3 to express Nterminal FLAG fusions [33]. Baculovirus shuttle plasmid pMA326 was constructed by PCR amplification of pMA323 with primer pair UL51-FLAG-BamHI/UL51FLAG-ER1R (which introduce flanking BamHI and EcoRI sites) and ligation of the BamHI/EcoRI-digested PCR product into BamHI/EcoRI-digested pFastbac1.

The UL56 coding sequence was assembled by PCR amplification of HCMV strain AD169 DNA using primer pairs MOL60/MOL64 and MOL59/MOL65 and cloning of the products into pGEM-T vector (Promega) to generate plasmids pMA48 and pMA49, respectively. An $\mathrm{NcoI} / \mathrm{XhoI}$ fragment of pMA48 was then ligated into NcoI/XhoI-restricted pFastbac-HTa (Invitrogen) to make plasmid pMA50 and an NcoI fragment from pMA48 was inserted into NcoI-digested pMA50 make plasmid pMA51. An Xhol/SalI fragment from pMA49 was then inserted into XhoI-digested pMA51 to make baculovirus shuttle plasmid pMA52. V5-UL56 expression plasmid pMA334 was constructed by PCR amplification of pMA52 with primer pair UL56-V5-F/UL56-V5-R, cloning the product into $\mathrm{pCR} 8 / \mathrm{GW} / \mathrm{TOPO}$ (Invitrogen) to make plasmid pMA325, and LR clonase transfer of the insert to pcDNA3.1/nV5-DEST (Invitrogen).

The cDNA of UL89 was prepared by RT-PCR of RNA isolated from MRC-5 cells 72 hours post infection with HCMV strain AD169 using ULTRASPEC RNA (BiotecX). The RT-PCR reaction used SuperScriptTM II RNase H 
Table 1 Oligonucleotides used for plasmid construction

\begin{tabular}{|c|c|c|c|}
\hline Plasmid & contains & Oligonucleotide & Sequence $\left(5^{\prime}-3^{\prime}\right)^{*}$ \\
\hline \multirow[t]{2}{*}{ pMA319 } & UL51 & MOL269 & ATGTCCTGGGCTAAGCAGCG \\
\hline & & MOL270 & TTATTAACCCGGCGCCGACT \\
\hline \multirow[t]{2}{*}{ pMA48 } & UL56 (5') & MOL60 & CCATGGAGATGAATTTGTTAC \\
\hline & & MOL64 & CTCCTCGAGAATATGCTTGAT \\
\hline \multirow[t]{2}{*}{ pMA49 } & UL56 (3') & MOL59 & ACAGGTTAACGCAGACTACCA \\
\hline & & MOL65 & ATATTCTCGAGGAGATTCGAC \\
\hline \multirow[t]{2}{*}{ pUL89 } & UL89 CDNA & MOL53 & CTGCTGCGTGCCTAGCTGAC \\
\hline & & MOL54 & CATCATGTTGCGCGGAGACT \\
\hline \multirow[t]{2}{*}{ pMA323 } & FLAG-UL51 & UL51-FLAG-H3F & GACCTAAGCTTTCCTGGGCTAAGCAGCGGGTG \\
\hline & & UL51-FLAG-ER1R & TACGATGAATTCTTATTTACCCGGCGCCGACTC \\
\hline \multirow[t]{2}{*}{ pMA326 } & $\overline{\text { FLAG-UL51 }}$ & UL51-FLAG-BamHI & CGGGATCCATGGACTACAAGGACGACGA \\
\hline & & UL51-FLAG-ER1R & TACGATGAATTCTTATTTACCCGGCGCCGACTC \\
\hline \multirow[t]{2}{*}{$\overline{\text { pMA325 }}$} & UL56 & UL56-V5-F & GAGATGAATTTGTTACAGAAACTA \\
\hline & & UL56-V5-R & TTAACGCAGACTACCAGGCAC \\
\hline \multirow[t]{4}{*}{$\overline{\text { pMA324 }}$} & MYC-UL89 & linkA & GATCCACCATGGAACAAAAACTCATCTCAGAAGAGGATCTGG \\
\hline & & linkB & AATTCCAGATCCTCTTCTGAGATGAGTTITGTTCCATGGTG \\
\hline & & UL89-NMyc-ER1F & CATGATGAATTCTTGCGCGGAGACTCGGCC \\
\hline & & UL89-NMyc-XB1R & TACATGTCTAGACTAGCTGACCCTGAAACG \\
\hline
\end{tabular}

*restriction sites used for cloning are underlined.

reverse transcriptase (Gibco BRL) and primer pair MOL53/ MOL54. The product was cloned into pGEM-T vector to make plasmid pUL89. An SpeI/SphI fragment of pUL89 containing UL89 cDNA sequences was then ligated into SpeI/SphI-restricted pFastbac1 to make baculovirus shuttle plasmid pMA38. MYC-UL89 expression plasmid pMA324 was constructed by ligation of annealed oligonucleotides linkA and linkB into EcoRI/BamHI-restricted pcDNA4/TO (Invitrogen) to make pcDNA4/TO-c-myc followed by insertion of an EcoRI fragment containing HSV-1 US11 to make pCDNA4/TO-myc-US11. US11 sequences were then removed by EcoRI/XbaI digestion and replaced with UL89 coding sequences by ligation to an EcoRI/XbaI-digested PCR product amplified from pMA38 using primer pair UL89-NMyc-ER1F/UL89-NMyc-XB1R (which introduce flanking EcoRI and XbaI sites). All expression vectors were verified by sequencing.

Baculovirus shuttle plasmids pMA326, pMA52, and pMA38 were used as directed in the BAC-to-BAC baculovirus system (Invitrogen, Grand Island, NY) to construct recombinant baculoviruses expressing FLAGUL51, 6xhis-UL56, and UL89, respectively.

\section{Immunoblotting}

Sf9 insect cells were infected with $3 \mathrm{pfu} / \mathrm{cell}$ of each baculovirus individually, or co-infected with pairwise combinations or with all three viruses. After $48 \mathrm{~h}$, cytoplasm was separated from nuclei by dounce homogenization in hypotonic buffer followed by lowspeed centrifugation as described [34]. Cytoplasmic supernatants were adjusted to $1 \mu \mathrm{g} / \mathrm{ml}$ aprotinin, leupeptin, and pepstain. Nuclei were suspended in 2 packed volumes of $20 \mathrm{mM}$ Tris- $\mathrm{HCl}, \mathrm{pH} 8.2,2 \mathrm{M} \mathrm{NaCl}, 2 \mathrm{mM}$ EDTA, $2 \mathrm{mM}$ 2-mercaptoethanol, $0.5 \mathrm{mM}$ phenylmethylsulfonylfluoride and rocked gently at $4^{\circ} \mathrm{C}$ for $30 \mathrm{~min}$. Nuclear fractions were clarified by centrifugation at $70,000 \times g$ for $30 \mathrm{~min}$. at $4^{\circ} \mathrm{C}$. Soluble nuclear and cytoplasmic extracts were separated by SDS-PAGE and electrophoretically transferred to nitrocellulose membranes. Membranes were probed with rabbit antisera to UL56 (WAR8, raised against an E. coli-expressed GST fusion to UL56 residues 383-850, a gift from Tom Jones), UL89 (WAR21, raised against an E. coliexpressed GST fusion to UL89 residues 1-296, a gift from Tom Jones), or histone H4 (ab 10158, Abcam), or with mouse monoclonal antibodies to FLAG (F3165, Sigma) or tubulin (ab 6161, Abcam). Blots were developed using goat anti-mouse (Jackson Immunotherapeutics) or anti-rabbit (Thermo) IgG conjugated to horse radish peroxidase and the SuperSignal West Pico (GE Healthcare) luminescent substrate, followed by exposure to X-ray film.

\section{Transient expression and confocal microscopy}

HEK-293 T cells were transfected with plasmid vectors individually or in combinations using Effectene (Qiagen). After $48 \mathrm{~h}$ the cells were permeabilized with cold methanol, blocked with phosphate buffered saline containing 1\% BSA, and stained either with fluorescein isothiocyanate (FITC)conjugated anti-V5 monoclonal antibody (Invitrogen), 
or unconjugated anti-MYC (Sigma) or M2 anti-FLAG monoclonal antibody (Sigma) followed by a FITCconjugated anti-mouse IgG1 (Serotec) secondary antibody. Cells were counterstained with $1 \mu \mathrm{g} / \mathrm{ml}$ of 4', 6-diamidino2phenylindole (DAPI). Images were collected using an LSM 510 Meta confocal laser scanning microscope with $63 \mathrm{X}$ oil immersion objective (numerical aperture 1.4), pinhole $0.7 \mu \mathrm{m}$, and excitation of $488 \mathrm{~nm}$ (FITC) or $405 \mathrm{~nm}$ (DAPI).

\section{Abbreviations}

HSV-1: Herpes simplex virus type 1; HCMV: Human cytomegalovirus; NLS: Nuclear localization signal; MCMV: Murine cytomegalovirus; FITC: Fluorescein isothiocyanate; DAPI: 4', 6-diamidino-2phenylindole (DAPI).

\section{Competing interests}

The authors declare that they have no competing interests.

\section{Authors' contributions}

JBW constructed the plasmid and baculovirus expression vectors and conducted the transient expression/confocal microscopy experiments. YZ conducted the baculovirus expression/immunoblot experiments. MM and DP conceived the experiments, interpreted the results, and prepared an initial draft of the manuscript. All authors were involved in revising the manuscript and have read and approved the final manuscript.

\section{Acknowledgments}

We thank Robert Tombes and Jennifer Fettweis for pcDNA-2FLAGAB Microscopy was performed at the VCU Department of Anatomy and Neurobiology Microscopy Facility, supported, in part, with funding from the NIH-NINDS Center core grant (5P30NS047463). This work was also supported in part by Public Health Services grants R01Al46668 and R21Al43527 (to M.A. M.) and by R01GM073832 (to D.S.P.).

\section{Author details}

'Department of Pediatrics, Virginia Commonwealth University, P.O. Box 163, MCV Station, Richmond, VA 23298-0163, USA. ${ }^{2}$ Department of Molecular Virology, Immunology, and Medical Genetics, Ohio State University, Columbus, OH 43210, USA.

Received: 6 August 2012 Accepted: 14 December 2012

Published: 21 December 2012

\section{References}

1. Brown JC, McVoy MA, Homa FL: Packaging DNA into Herpesvirus Capsids. In Structure-Function Relationships of Human Pathogenic Viruses. Edited by Bogner E, Holzenburg A. London: Kluwer Academic/Plenum Publishers; 2002.

2. Hwang JS, Bogner E: ATPase activity of the terminase subunit pUL56 of human cytomegalovirus. J Biol Chem 2002, 277:6943-6948.

3. Thoma C, Borst E, Messerle M, Rieger M, Hwang JS, Bogner E: Identification of the interaction domain of the small terminase subunit pUL89 with the large subunit pUL56 of human cytomegalovirus. Biochemistry 2006, 45:8855-8863.

4. Borst EM, Kleine-Albers J, Gabaev I, Babic M, Wagner K, Binz A, Degenhardt I, Kalesse M, Jonjic S, Bauerfeind R, Messerle M: The human cytomegalovirus UL51 protein is essential for viral genome cleavage-packaging and interacts with the terminase subunits pUL56 and pUL89. J Virol 2012, [Epub ahead of print].

5. Koslowski KM, Shaver PR, Wang XY, Tenney DJ, Pederson NE: The pseudorabies virus UL28 protein enters the nucleus after coexpression with the herpes simplex virus UL15 protein. J Virol 1997, 71:9118-9123.

6. Koslowski KM, Shaver PR, Casey JT 2nd, Wilson T, Yamanaka G, Sheaffer AK, Tenney DJ, Pederson NE: Physical and functional interactions between the herpes simplex virus UL15 and UL28 DNA cleavage and packaging proteins. J Virol 1999, 73:1704-1707.

7. Abbotts AP, Preston VG, Hughes M, Patel AH, Stow ND: Interaction of the herpes simplex virus type 1 packaging protein UL15 with full-length and deleted forms of the UL28 protein. J Gen Virol 2000, 81:2999-3009.
8. Beard PM, Taus NS, Baines JD: DNA cleavage and packaging proteins encoded by genes $\mathrm{U}(\mathrm{L}) 28, \mathrm{U}(\mathrm{L}) 15$, and $\mathrm{U}(\mathrm{L}) 33$ of herpes simplex virus type 1 form a complex in infected cells. J Virol 2002, 76:4785-4791.

9. Yang K, Baines JD: The putative terminase subunit of herpes simplex virus 1 encoded by UL28 is necessary and sufficient to mediate interaction between pUL15 and pUL33. J Virol 2006, 80:5733-5739.

10. Fuchs W, Klupp BG, Granzow H, Leege T, Mettenleiter TC: Characterization of pseudorabies virus (PrV) cleavage-encapsidation proteins and functional complementation of PrV pUL32 by the homologous protein of herpes simplex virus type 1. J Virol 2009, 83:3930-3943.

11. Yang K, Poon AP, Roizman B, Baines JD: Temperature-sensitive mutations in the putative herpes simplex virus type 1 terminase subunits pUL15 and pUL33 preclude viral DNA cleavage/packaging and interaction with pUL28 at the nonpermissive temperature. J Virol 2008, 82:487-494.

12. Jacobson JG, Yang K, Baines JD, Homa FL: Linker insertion mutations in the herpes simplex virus type 1 UL28 gene: effects on UL28 interaction with UL15 and UL33 and identification of a second-site mutation in the UL15 gene that suppresses a lethal UL28 mutation. J Virol 2006, 80:12312-12323.

13. Beilstein F, Higgs MR, Stow ND: Mutational analysis of the herpes simplex virus type 1 DNA packaging protein UL33. J Virol 2009, 83:8938-8945.

14. Visalli RJ, Knepper J, Goshorn B, Vanover K, Burnside DM, Irven K, McGauley $R$, Visalli M: Characterization of the Varicella-zoster virus ORF 25 gene product: pORF25 interacts with multiple DNA encapsidation proteins. Virus Res 2009, 144:58-64.

15. Visalli RJ, Nicolosi DM, Irven KL, Goshorn B, Khan T, Visalli MA: The Varicellazoster virus DNA encapsidation genes: Identification and characterization of the putative terminase subunits. Virus Res 2007, 129:200-211.

16. Uetz P, Dong YA, Zeretzke C, Atzler C, Baiker A, Berger B, Rajagopala SV, Roupelieva M, Rose D, Fossum E, Haas J: Herpesviral protein networks and their interaction with the human proteome. Science 2006 , 311:239-242.

17. Fossum E, Friedel CC, Rajagopala SV, Titz B, Baiker A, Schmidt T, Kraus T, Stellberger T, Rutenberg C, Suthram S, et al: Evolutionarily conserved herpesviral protein interaction networks. PLoS Pathog 2009, 5:e1000570.

18. Giesen K, Radsak K, Bogner E: The potential terminase subunit of human cytomegalovirus, pUL56, is translocated into the nucleus by its own nuclear localization signal and interacts with importin alpha. J Gen Virol 2000, 81:2231-2244.

19. Giesen K, Radsak K, Bogner E: Targeting of the gene product encoded by ORF UL56 of human cytomegalovirus into viral replication centers. FEBS Lett 2000, 471:215-218.

20. Vizoso Pinto MG, Pothineni VR, Haase R, Woidy M, Lotz-Havla AS, Gersting SW, Muntau AC, Haas J, Sommer M, Arvin AM, Baiker A: Varicella zoster virus ORF25 gene product: an essential hub protein linking encapsidation proteins and the nuclear egress complex. J Proteome Res 2011, 10:5374-5382.

21. Varnum SM, Streblow DN, Monroe ME, Smith P, Auberry KJ, Pasa-Tolic L, Wang D, Camp DG 2nd, Rodland K, Wiley S, et al: Identification of Proteins in Human Cytomegalovirus (HCMV) Particles: the HCMV Proteome. J Virol 2004, 78:10960-10966.

22. Kattenhorn LM, Mills R, Wagner M, Lomsadze A, Makeev V, Borodovsky M, Ploegh HL, Kessler BM: Identification of proteins associated with murine cytomegalovirus virions. J Virol 2004, 78:11187-11197.

23. Underwood MR, Harvey RJ, Stanat SC, Hemphill ML, Miller T, Drach JC, Townsend LB, Biron KK: Inhibition of human cytomegalovirus DNA maturation by a benzimidazole ribonucleoside is mediated through the UL89 gene product. J Virol 1998, 72:717-725.

24. Underwood MR, Ferris RG, Selleseth DW, Davis MG, Drach JC, Townsend LB, Biron KK, Boyd FL: Mechanism of action of the ribopyranoside benzimidazole GW275175X against human cytomegalovirus. Antimicrob Agents Chemother 2004, 48:1647-1651.

25. Buerger I, Reefschlaeger J, Bender W, Eckenberg P, Popp A, Weber O, Graeper $S$, Klenk HD, Ruebsamen-Waigmann H, Hallenberger S: A novel nonnucleoside inhibitor specifically targets cytomegalovirus DNA maturation via the UL89 and UL56 gene products. J Virol 2001, 75:9077-9086.

26. Krosky PM, Underwood MR, Turk SR, Feng KW, Jain RK, Ptak RG, Westerman AC, Biron KK, Townsend LB, Drach JC: Resistance of human cytomegalovirus to benzimidazole ribonucleosides maps to two open reading frames: UL89 and UL56. J Virol 1998, 72:4721-4728. 
27. van Zeijl M, Fairhurst J, Jones TR, Vernon SK, Morin J, LaRocque J, Feld B, O'Hara B, Bloom JD, Johann SV: Novel class of thiourea compounds that inhibit herpes simplex virus type 1 DNA cleavage and encapsidation: resistance maps to the UL6 gene. J Virol 2000, 74:9054-9061.

28. Hwang JS, Kregler O, Schilf R, Bannert N, Drach JC, Townsend LB, Bogner E: Identification of acetylated, tetrahalogenated benzimidazole Dribonucleosides with enhanced activity against human cytomegalovirus. J Virol 2007, 81:11604-11611.

29. Goldner T, Hewlett G, Ettischer N, Ruebsamen-Schaeff H, Zimmermann H, Lischka P: The novel anticytomegalovirus compound AIC246 (Letermovir) inhibits human cytomegalovirus replication through a specific antiviral mechanism that involves the viral terminase. J Virol 2011, 85:10884-10893.

30. Lischka P, Zimmermann H: Antiviral strategies to combat cytomegalovirus infections in transplant recipients. Curr Opin Pharmacol 2008, 8:541-548.

31. Marschall M, Stamminger T, Urban A, Wildum S, Ruebsamen-Schaeff $H$, Zimmermann H, Lischka P: In vitro evaluation of the activities of the novel anti-cytomegalovirus compound AIC246 (letermovir) against herpesviruses and other human pathogenic viruses. Antimicrob Agents Chemother 2011, 56(2):1135-1137.

32. Harter G, Michel D: Antiviral treatment of cytomegalovirus infection: an update. Expert Opin Pharmacother 2012, 13:623-627.

33. Seward ME, Easley CA, McLeod JJ, Myers AL, Tombes RM: Flightless-I, a gelsolin family member and transcriptional regulator, preferentially binds directly to activated cytosolic CaMK-II. FEBS Lett 2008, 582:2489-2495.

34. Chaudhuri M, Parris DS: Evidence against a simple tethering model for enhancement of herpes simplex virus DNA polymerase processivity by accessory protein UL42. J Virol 2002, 76:10270-10281.

doi:10.1186/1743-422X-9-315

Cite this article as: Wang et al:: Changes in subcellular localization reveal interactions between human cytomegalovirus terminase subunits. Virology Journal 2012 9:315.

\section{Submit your next manuscript to BioMed Central and take full advantage of:}

- Convenient online submission

- Thorough peer review

- No space constraints or color figure charges

- Immediate publication on acceptance

- Inclusion in PubMed, CAS, Scopus and Google Scholar

- Research which is freely available for redistribution 